\title{
EVALUACIÓN DE TRES NIVELES DE NITRÓGENO EN MEDIO DE CULTIVO, EN LAS FASES DE ENRAIZAMIENTO in vitro $Y$ ADAPTACIÓN A SUSTRATO DE Rubus glaucus (BENTH)
}

\author{
Evaluation of Three Levels of Nitrogen in Culture Medium, in in \\ vitro Rooting And Adaptation to Substrate Phases of Rubus Glaucus \\ (Benth)
}

\author{
Ivonne Vaca ${ }^{1}$ y Pablo Landázuri ${ }^{2}$
}

\author{
1 Universidad Politécnica Salesiana, Centro de Investigación y Valoración de la Biodiversidad CIVABI, Av. 12 de Octubre N24-22 \\ y Wilson, Quito, Ecuador. Teléfono: 593-023962800. \\ 2 Universidad de las Fuerzas Armadas ESPE, Campus Politécnico Av. Gral. Rumiñahui s/n Sangolquí, Ecuador.
}

Autor para correspondencia: ivonne.vaca@gmail.com, ivaca@ups.edu.ec

Manuscrito recibido el 6 de septiembre de 2013. Aceptado, tras revisión, el 12 de noviembre de 2013.

\begin{abstract}
Resumen
El presente trabajo fue desarrollado en el Cantón Rumiñahui, provincia de Pichincha, Ecuador. El objetivo fue evaluar tres concentraciones nitrógeno de las sales Murashige y Skooog (MS) en el medio de cultivo, en las fases de enraizamiento in vitro y adaptación a sustrato de Rubus glaucus. La dosis de 4,88mM de nitrógeno en el medio presentó el mayor número de raíces con un promedio de 3,72 raíces por planta, mayor longitud de raíz con $1,8 \mathrm{~cm}$ de largo, mayor porcentaje de enraizamiento tanto in vitro como en sustrato, con un promedio de $78 \%$ y $100 \%$ respectivamente. Además, resultó en los menores niveles de estrés de la planta, medidos en el índice del contenido de clorofila y actividad del fotosistema II o fluorescencia variable. Los resultados muestran que la disminución de los nitratos a la mitad, fue un factor determinante en el incremento de plantas enraizadas.
\end{abstract}

Palabras claves: Rubus glaucus (Benth), cultivo in vitro, enraizamiento, adaptación a sustrato, nitrógeno.

\begin{abstract}
This work was developed in canton Rumiñahui, Pichincha province, Ecuador. The objective of this work was to evaluate three nitrogen concentrations of Murashige and Skooog salts (MS) in the culture medium, during the stages rooting in vitro and substrate adaptation of Rubus glaucus. The $4.88 \mathrm{mM}$ dose of nitrogen in the medium had the highest number of roots with an average of 3.72 roots per plant, increased root length of $1.8 \mathrm{~cm}$ long, percentage of rooting in vitro and in substrate, with an average $78 \%$ and $100 \%$ respectively. Also resulted in lower levels of plant stress, measured in the index of chlorophyll content and photosystem II activity or variable fluorescence. The results show that the half of nitrates was a major factor in increasing rooted plants.
\end{abstract}

Keywords: Rubus glaucus (Benth), in vitro culture, rooting, substrate adaptation, nitrogen.

Forma sugerida de citar: Vaca, I. y P. Landázuri. 2013. Evaluación de tres niveles de nitrógeno en medio de cultivo, en las fases de enraizamiento in vitro y adaptación a sustrato de Rubus glaucus (Benth). La Granja. Vol. 18(2): 48-54. ISSN: 1390-3799. 


\section{Introducción}

Rubus glaucus, denominada comúnmente como mora de castilla, es una especie nativa de Los Andes, de uso comestible. Esta es la variedad que más se cultiva en el Ecuador, debido a su gran demanda tanto en el mercado interno como externo (Marulanda et al., 2000; PROFIAGRO, 2007). La mora es cultivada comercialmente en diferentes países de América, como: Colombia, Ecuador, Chile, Panamá, Guatemala, México y Canadá (Ledin, 1955; PROFIAGRO, 2007; CAQ, 1992). Actualmente, en nuestro país, se cultiva en los Valles del Callejón interandino y en las estribaciones de la Sierra, su cultivo alcanza las 5247 hectáreas, su mayor parte está en manos de pequeños y medianos productores, que tienen entre 200 hasta 2000 plantas en producción (PROFIAGRO, 2007).

Para el cultivo de mora de castilla, los sistemas de reproducción, son tanto sexual como asexual. Se usa principalmente el sistema asexual, debido a la baja cantidad de semillas fértiles en cada fruto, bajo poder germinativo, largo período de germinación y lento desarrollo de las plántulas (CAQ, 1992). Sin embargo, en la propagación asexual los problemas esenciales son: la diseminación de enfermedades internas de la planta madre y la pérdida de variabilidad genética (Raisman y González, 2008).

Debido a la falta de plantas certificadas en el país, se hace necesario buscar alternativas que permitan propagar plantas enraizadas de mora libres de patógenos. Lo que ha llevado a considerar al uso de cultivos in vitro como una herramienta para obtener plantas de calidad (PROFIAGRO, 2007). Si bien es cierto, los diversos métodos de propagación para el cultivo de mora de castilla, presentan tanto ventajas como desventajas, el presente proyecto plantea establecer un método de enraizamiento in vitro del cultivo, que permita al propagador la producción de plantas sanas a gran escala.

\section{Materiales y Métodos}

\subsection{Ubicación geográfica}

El proyecto se desarrolló en el Laboratorio de Control Biológico de la Carrera de Ciencias Agropecuarias - IASA I, de la Escuela Politécnica del Ejército (ESPE), ubicada en Ecuador, provincia de Pichincha, cantón Rumiñahui, parroquia San Fernando, en la Hacienda "El Prado", a 78 24' 44" (O) y 0 23' 20" (S), a una altitud de 2748 m.s.n.m. Bajo condiciones controladas, en un cuarto de crecimiento con una temperatura entre $20-25^{\circ} \mathrm{C}$ y humedad relativa entre 43 y $60 \%$.

\subsection{Materiales}

Los reactivos utilizados para el protocolo de desinfección de mora fueron hipoclorito de sodio, jabón líquido y fungicidas. Para el cultivo in vitro de mora, se utilizó medio MS modificado, cuya composición es sales MS, ácido nicotínico, piridoxina, tiamina, glicina, sucrosa, agar, polovinil pirrolidona (PVP), ácido cítrico y BAP (Benzil amino purina).

\subsection{Material vegetal y siembra en medio de cultivo}

Las varetas de mora fueron tomadas de la parte media alta de una misma planta de mora de castilla, cultivada bajo condiciones de invernadero; estas tuvieron una longitud promedio de $30 \mathrm{~cm}$, cuyo número de yemas útiles varió entre 3 y 12 . Fueron llevadas al laboratorio y desinfectadas, se introdujeron en medio MS modificado, sembrando un explante por tubo, durante dos semanas.

Los brotes adaptados al medio de introducción, sin contaminación, pasaron al medio de multiplicación MS modificado, durante 2 meses.

\subsection{Enraizamiento in vitro}

Los explantes de mora provenientes de la fase de multiplicación, fueron divididos y pasados al medio de enraizamiento, donde permanecieron durante 35 días, hasta el aparecimiento de raíces.

En la fase de enraizamiento, se evaluó la concentración de nitrógeno total, proveniente de las sales inorgánicas adicionadas en el medio modificado con benzil amino purina (BAP) en dosis fija (1ppm) (Tabla 1), para la formación de raíces in vitro (Figura 1).

Las dosis propuestas en los tratamientos se basan en el contenido total de nitrógeno de las sales MS, correspondiendo la concentración de $9,75 \mathrm{mM}$ de nitrógeno total al $100 \%$ de sales MS; mientras que el $4.88 \mathrm{mM}$ corresponde al $50 \%$ de sales MS. En la concentración 7,48 mM, se evalúa el $100 \%$ de sales 
MS excepto el Nitrato de potasio, que se disminuyó al $25 \%$ de su concentración; de esta manera también varía la relación nitrato/amonio en el medio de cultivo.

Tabla 1. Concentración total de Nitrógeno en el medio de enraizamiento in vitro. Fuente: Pati et al. (2005)

\begin{tabular}{lcc}
\hline & Tratamiento & $\begin{array}{c}\text { Concentración de N } \\
\text { total (mM) }\end{array}$ \\
\hline $\mathrm{T} 1$ & Sales MS 100\% & 9,75 \\
$\mathrm{~T} 2$ & Sales MS 100\% y & 7,48 \\
$\mathrm{~T} 3$ & $\mathrm{KNO}_{3} 25 \%$ & 4,88 \\
\hline
\end{tabular}

\subsection{Adaptación a sustrato}

Los tratamientos de la fase de enraizamiento in vitro fueron pasados a sustrato, para su adaptación. Durante esta fase, las plantas fueron etiquetadas y evaluadas en función de los tratamientos in vitro. Las plantas fueron regadas con agua destilada estéril (ADE) dos veces por semana, durante los 28 días de evaluación.

La unidad experimental para la fase de enraizamiento in vitro fue un contenedor plástico $(12,5 \mathrm{~cm}$ de diámetro y $13 \mathrm{~cm}$ de longitud), con cuatro explantes de mora.

Los tratamientos para la fase de enraizamiento in vitro se dispusieron bajo un diseño completamente al azar en arreglo factorial $3 \times 3$, con tres repeticiones.

La unidad experimental para la fase de adaptación a sustrato fueron cuatro explantes de mora por tratamiento, en una bandeja forestal de 38 alveolos. La bandeja abarcó una repetición de cada uno de los tratamientos de enraizamiento in vitro (Fig 1).

Los tratamientos para la fase de adaptación a sustrato se dispusieron bajo un diseño completamente al azar en arreglo factorial $3 \times 3$, con tres repeticiones; es decir una bandeja por cada una de ellas.

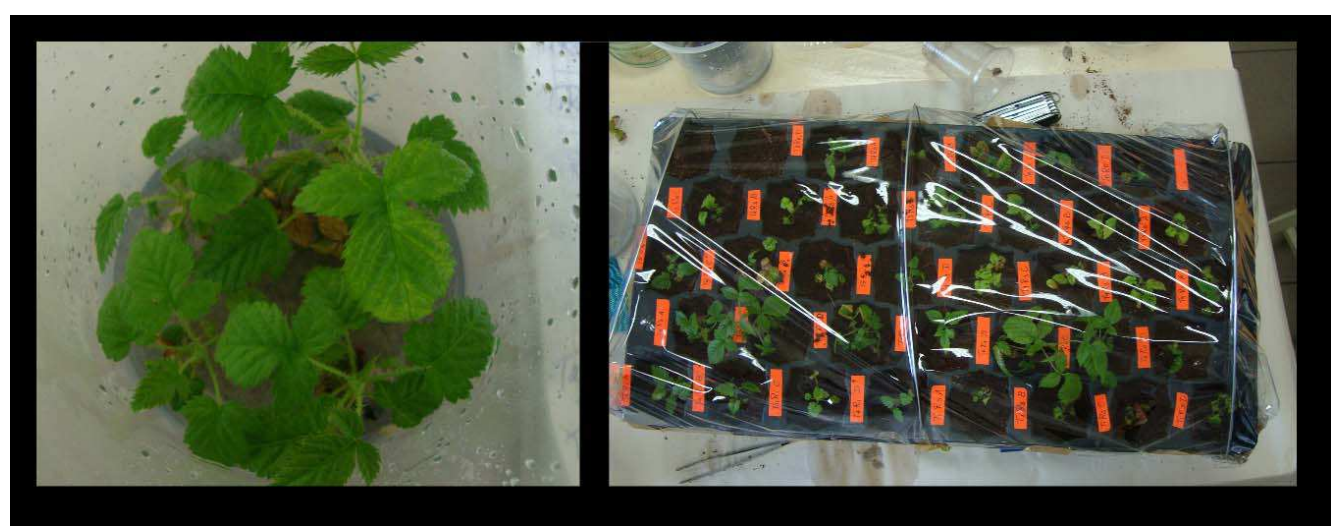

Figura 1. Cultivo in vitro y adaptación a sustrato de Rubus glaucus.

Las variables evaluadas durante la fase de enraizamiento in vitro, fueron:

Número de raíces: se contabilizó la cantidad de raíces por explante formadas al final de esta fase.

Longitud de la raíz: se midió la longitud de la raíz en centímetros $(\mathrm{cm})$, desde el cuello (unión de la raíz y el tallo) hasta el extremo más largo, una sola vez a la salida de esta fase.

Porcentaje de plantas enraizadas in vitro: se contabilizó el número de individuos que enraizaron, en relación con la población total de tratamientos.
Las variables evaluadas durante la fase de adaptación a sustrato, fueron:

Porcentaje de plantas enraizadas en sustrato: se contabilizó el número de individuos que enraizaron, en relación a la población total de tratamientos.

Las variables evaluadas durante la fase de enraizamiento, tanto in vitro como en adaptación a sustrato, fueron:

La actividad fotosistema II (Fv/Fm): se midió la actividad del fotosistema II (FSII) mediante el uso de un Fluorómetro modelo OS-30p, antes de la in- 
troducción al medio de enraizamiento; al finalizar la fase de enraizamiento y la de adaptación a sustrato. Para las mediciones, se tomó una hoja de cada explante de mora; se colocó la pinza con el paso de luz cerrado durante 5 min; se abrió la ranura para permitir el paso de la luz e, inmediatamente, se colocó la pinza en el lector.

Índice de clorofila (ICC): se midió el índice de contenido de clorofila, mediante un clorómetro modelo CCM200, antes de la introducción al medio de enraizamiento, al finalizar la fase de enraizamiento y la de adaptación a sustrato. Para la medición del contenido de clorofila, se calibró el medidor de clorofila en la oscuridad durante 5 segundos y se colocó una hoja de mora en el lector.

\section{Resultados y Discusión}

\subsection{Número y longitud de la raíz}

En la Tabla 2, se presenta el número de raíces formadas por explante y la longitud de la raíz en cm para los tres niveles de nitrógeno en el medio de cultivo.

Tabla 2. Promedio $( \pm)$ el error estándar del número de raíces y longitud de la raíz in vitro, para la concentración de nitrógeno en el medio de enraizamiento. Valores seguidos por letras diferentes son significativamente distintos $(p \leq 0,05)$.

\begin{tabular}{ccc}
\hline $\begin{array}{c}\text { [N] } \\
\text { nM }\end{array}$ & $\begin{array}{c}\text { Número de } \\
\text { raíces }\end{array}$ & $\begin{array}{c}\text { Longitud de la raíz } \\
(\mathbf{c m})\end{array}$ \\
\hline 9,75 & $0,74 \pm 0,28 a$ & $0,52 \pm 0,17 a$ \\
7,48 & $3,03 \pm 0,67 b$ & $1,68 \pm 0,29 b$ \\
4,88 & $3,72 \pm 0,58 b$ & $1,80 \pm 0,25 b$ \\
\hline
\end{tabular}

Tanto la variable número de raíces como longitud de la raíz presentan diferencias significativas para la concentración de nitrógeno en el medio de cultivo $(F=9,75, p=0,0001 ; F=9,99, p=0,0001)$, con un coeficiente de variación 12,66 y 10,87 respectivamente. La concentración de $4,88 \mathrm{mM}$ de nitrógeno, es decir nitratos reducidos a la mitad en el medio, presentaron el mayor número de raíces con 3,72 raíces por explante y mayor longitud de raíz, con un promedio $1,8 \mathrm{~cm}$ (Tabla 2, Figura 2). Alev y Arslan (2006) indican haber obtenido el mayor número de raíces en rosas, con un promedio de 5,6 raíces, cultivando en medio MS formulado a la mitad de la concentración de macro, microsales y vitaminas; mientras que los cultivos en medio MS completo y diluido 1 / 4 de la concentración, obtuvieron promedios de longitud de raíz bajos, con valores de 1,91 y 0,67 respectivamente.

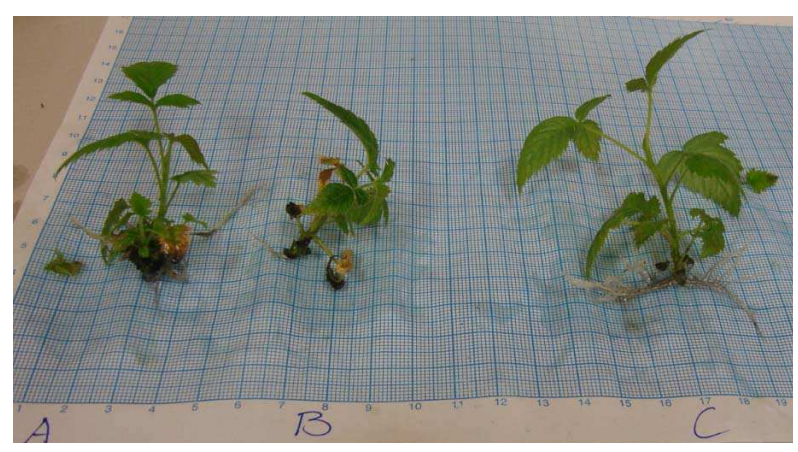

Figura 2. Plantas enraizadas in vitro. A 9,75 mM (T1). B 7,48 mM (T2). B 4,88 mM (T3).

Hyndman et al. (1982) lograron obtener un mayor número y longitud de raíces in vitro, de $R$. hybrida cv. "Improved Blaze", al disminuir la concentración total de nitrógeno de las sales MS en el medio, así se logró la concentración de las otras sales constante. Además, reportan que al evaluar independientemente las concentraciones de nitrato $\left(\mathrm{NO}_{3}\right)$ y amonio $\left(\mathrm{NH}_{4}\right)$, ninguno de los tratamientos tiene el mismo efecto de enraizamiento, que cuando se disminuyen juntos, pues mantienen la misma relación $\mathrm{NO}_{3} / \mathrm{NH}_{4}$. Resultados que coinciden con los obtenidos en el presente estudio, ya que la concentración $4,88 \mathrm{mM}$ de nitrógeno ( $1 / 2$ de sales), que mantiene la misma relación $\mathrm{NO}_{3} / \mathrm{NH}_{4}$ que MS completo, produjo el mayor número y longitud de raíces. Ma et al. (1996) y Wu et al. (2009) también reportan resultados que concuerdan con los obtenidos en el presente estudio en la fase de enraizamiento.

\subsection{Porcentaje de plantas enraizadas}

Para la variable porcentaje de plantas enraizadas en la fase in vitro, se determinó que existía diferencia significativa para concentraciones de nitrógeno en el medio ( $F=16,67, p=-0,0001)$ con un coeficiente de variación de 8,08. Las concentraciones de 7,48 y $4,88 \mathrm{mM}$ de nitrógeno en el medio, presentaron un porcentaje de enraizamiento de 61 y $78 \%$ respectivamente (Tabla 3 ). 
La dilución de las sales en el medio de cultivo, puede influenciar positivamente en el enraizamiento de las plantas. Alev y Arslan (2006) obtuvieron la mayor frecuencia de enraizamiento con un $50 \%$ de explantes de rosa enraizados, en un medio que contenía la mitad de las sales de MS. Además, según Ramírez y Angarita (1990) se obtuvo un $100 \%$ de enraizamiento in vitro de plantas de mora, con los macroelementos diluidos a la quinta parte; por lo que recomienda la dilución de los macroelementos en el medio de cultivo para mejorar los porcentajes de supervivencia y enraizamiento. Estos resultados se relacionan con los obtenidos por Wu et al. (2009) que indican que una reducción de sales de un medio a un quinto, mejoran el enraizamiento de algunas especies del género Rubus hasta llegar a un $85 \%$ de plantas enraizadas.

Luna et al. (2004), recomiendan el medio MS diluido 4 veces, para el enraizamiento in vitro de Ilex dumosa. Hyndman et al. (1982) demostró que la disminución de la concentración de $\mathrm{KNO}_{3}$ y $\mathrm{NH}_{4} \mathrm{NO}_{3}$ fue un factor decisivo para el mejoramiento en el porcentaje de enraizamiento en rosa; lo que concuerda con Asadi et al. (2009) y Salek y Tarinejad (2011).

Tabla 3. Promedio $( \pm)$ el error estándar del porcentaje de plantas enraizadas in vitro y en sustrato,para la concentración de nitrógeno en el medio. Valores seguidos por letras diferentes son significativamente distintos $(p \leq 0,05)$.

\begin{tabular}{ccc}
\hline $\begin{array}{c}\text { [N] } \\
\text { nM }\end{array}$ & $\begin{array}{c}\text { \% plantas } \\
\text { enraizadas in vitro }\end{array}$ & $\begin{array}{c}\text { \% plantas enraizadas } \\
\text { en sustrato }\end{array}$ \\
\hline 9,75 & $22 \pm 7 a$ & $85 \pm 6 a$ \\
7,48 & $61 \pm 8 b$ & $95 \pm 5 a b$ \\
4,88 & $78 \pm 7 b$ & $100 \pm 0 b$ \\
\hline
\end{tabular}

Para la variable porcentaje de plantas enraizadas en la fase de adaptación a sustrato (Figura 3), se determinó que existió diferencia significativa para concentraciones de nitrógeno en el medio $(F=4,27$, $p=0,0169$ ) con un coeficiente de variación de 17,92 . La concentración 4,88 mM de nitrógeno en el medio, presentó $100 \%$ de plantas enraizadas en la fase de sustrato (Tabla 3); lo que coincide con los resultados obtenidos por Ramírez y Angarita (1990), quienes obtuvieron un $100 \%$ de plantas de mora enraizadas con MS diluido. Wu et al. (2009) reporta una supervivencia del $98 \%$ en la fase de adaptación a sustrato, de explantes de rosa in vitro provenientes de medios de cultivo con sales diluidas.

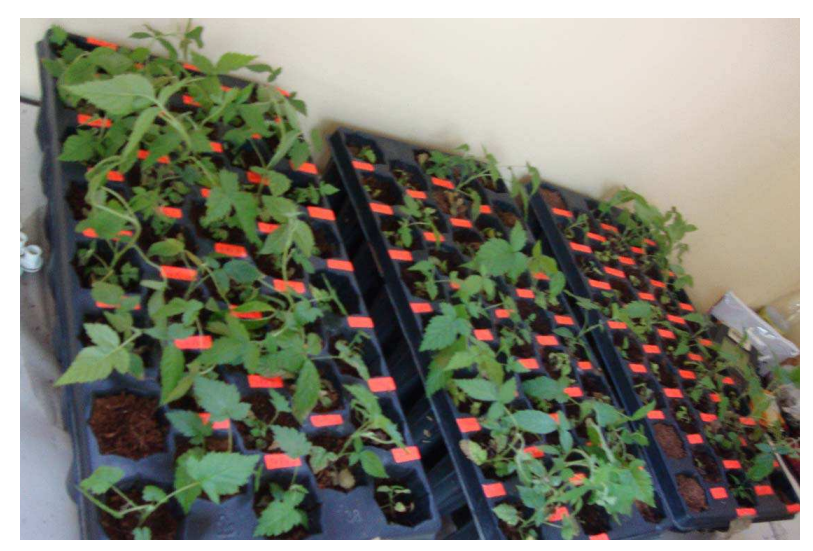

Figura 3. Plantas de mora adaptadas a sustrato.

\section{3 Índice del contenido de clorofila y ac- tividad del Fotosistema II}

Para la variable Índice del contenido de clorofila en la fase in vitro, se determinó que existió diferencia significativa para la concentración de nitrógeno en el medio $(F=12,85, p=-0,0001)$ con un coeficiente de variación de 5,30. De igual manera, para la variable Índice del contenido de clorofila en la fase adaptación a sustrato, se determinó que existió diferencia significativa para la concentración de nitrógeno en el medio $(F=14,11, p=-0,0001)$ con un coeficiente de variación de 4,53 . La concentración de $4,88 \mathrm{mM}$ de nitrógeno en el medio, presentó el mayor valor del índice de contenido de clorofila tanto en la fase in vitro como en adaptación a sustrato, con valores de 8,16 y 7,79 respectivamente (Tabla 4).

En la Figura 4, se presenta la regresión lineal entre las variables porcentaje de plantas enraizadas en sustrato e índice del contenido de clorofila en sustrato, para las tres concentraciones de nitrógeno en estudio $\left(R^{2}=1,00, p=0,03\right)$. En el gráfico, se observa que el índice del contenido de clorofila mantiene una relación directa con el porcentaje de enraizamiento. De las variables relacionadas, se desprende que a medida que el porcentaje de enraizamiento incrementa, el contenido de clorofila aumenta también en la planta; esto se debe a que las raíces absorben de mejor manera los nutrientes. 
Tabla 4. Promedio $( \pm)$ el error estándar del índice de contenido de clorofila (ICC) y actividad del fotosistema II (FSII), en la fase de enraizamiento in vitro y adaptación a sustrato, para la concentración de nitrógeno en el medio. Valores seguidos por letras diferentes son significativamente distintos $(p \leq 0,05)$.

\begin{tabular}{ccccc}
\hline $\begin{array}{c}\text { [N] } \\
\mathbf{n M}\end{array}$ & ICC in vitro & ICC en sustrato & $\begin{array}{c}\text { Actividad FSII } \text { in } \\
\text { vitro }\end{array}$ & $\begin{array}{c}\text { Actividad FSII } \\
\text { en sustrato }\end{array}$ \\
\hline 9,75 & $4,95 \pm 0,44 a$ & $4,33 \pm 0,53 a$ & $0,66 \pm 0,02 a$ & $0,65 \pm 0,03 a$ \\
7,48 & $4,89 \pm 0,60 a$ & $6,49 \pm 0,52 b$ & $0,70 \pm 0,03 a b$ & $0,74 \pm 0,02 b$ \\
4,88 & $8,16 \pm 0,57 b$ & $7,79 \pm 0,34 b$ & $0,75 \pm 0,01 b$ & $0,75 \pm 0,02 b$ \\
\hline
\end{tabular}

Además, dado que la concentración del nitrógeno en el medio tiene una relación inversamente proporcional tanto con el porcentaje de enraizamiento como con el índice de clorofila; es decir, que las plantas que provienen de una menor concentración de nitrógeno presentan mayor porcentaje de enraizamiento, así como mayor contenido de clorofila. Ya que el índice de contenido de clorofila es inversamente proporcional al grado de estrés (Zarco et al., 2000, 2001), se determina entonces que a menor concentración de nitrógeno en el medio habrá mayor enraizamiento y menor estrés en la planta.

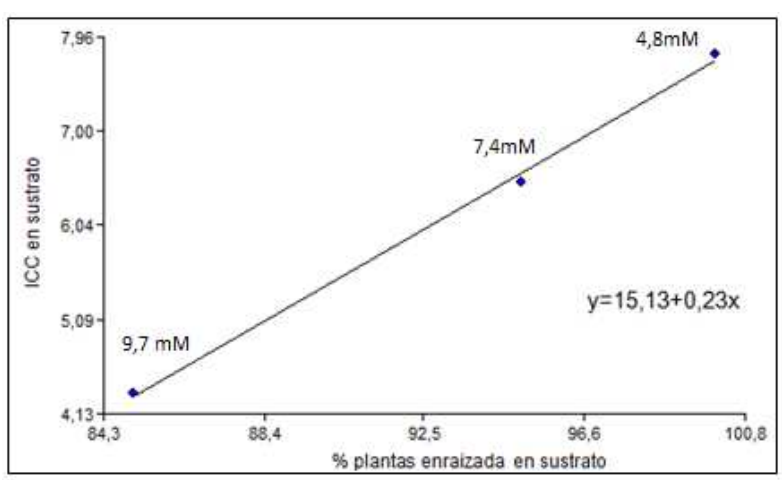

Figura 4. Regresión lineal entre porcentaje de plantas enraizadas e Índice del contenido de clorofila en sustrato, para las tres concentraciones de nitrógeno $(\mathrm{mM})$.

Para la variable actividad del fotosistema II o fluorescencia variable tanto en la fase in vitro como de adaptación a sustrato, se determinó que existió diferencia significativa para la concentración de nitrógeno en el medio. Para la fase in vitro $(F=4,90$, $p=0,0095)$ con un coeficiente de variación de $7,95 \mathrm{y}$ para la adaptación a sustrato $(F=4,13, p=0,0191)$ con un coeficiente de variación de 21,78 , la mayor fluorescencia variable se obtuvo en los tratamientos con una concentración de $4,88 \mathrm{mM}$ de nitrógeno en el medio, con un valor promedio de 0,75 para ambas fases (Tabla 4). Björkman y Demming (1987) citados por Cerrillo et al. (2004), y Zanandrea et al. (2006) reportan que 0,83 es un valor considerado óptimo para la fluorescencia variable, para una gran cantidad de especies, en un rango de 0,75 a 0,85 para hojas $e x$ vitro no estresadas. Además, Zarco et al. (2000) indican que los valores de Fv/Fm superiores a 0,83 correspondieron a zonas de estrés bajo, mientras que los valores inferiores a 0,69 correspondieron a zona de estrés alto. En los resultados obtenidos, la concentración 9,75 mM de nitrógeno en el medio, presentó valores de Fv / Fm inferiores a 0,66; lo que indica que a mayor concentración de sales en el medio, las plantas de mora presentaron mayor estrés.

\section{Conclusiones}

Al término del presente trabajo se concluyó lo siguiente:

La concentración 4,88 mM de nitrógeno en el medio de cultivo permitió la obtención del mayor número de raíces, longitud de raíces, porcentaje de enraizamiento in vitro y porcentaje de enraizamiento en sustrato, con promedios de 3,72 raíces por explante, $1,8 \mathrm{~cm}, 78 \%$ y $100 \%$, respectivamente.

La mitad de sales de nitrógeno en el medio $(4,88 \mathrm{mM})$, presentó el menor nivel de estrés vegetal, medido mediante los altos índices de contenido de clorofila (ICC) y actividad del fotosistema II ( $\mathrm{Fv} / \mathrm{Fm})$.

\section{Referencias}

Alev, C. y O. Arslan. 2006. Efficiente micropropagation of english shrub rose "heritage" under in vitro conditions. International Journal of Agrivulture and Biology, 8(5): 626-629. 
Asadi, A., M. Vedadi, C. Rahimi y B. Naserian. 2009. Effect of plant growth hormones on root and shoot regeneration in Rose (Morrasia) under invitro conditions.

Björkman, O. y B. Demming. 1987. Photon yield of 02 evolution and chlorophyill fluorescence characteristics at $77 \mathrm{k}$ among vascular plants of diverse origin. Planta, New York, 170: 489-504.

Centro Agrícola de Quito (CAQ). 1992. Manual técnico del cultivo de la mora de castilla. Convenio C.A.F., págs. 3-11.

Cerrillo, R., R. Maldonado y D. Ariza. 2004. Fluorescencia de la clorofila en cinco procedencias de pinus halepensis mill y su respuesta a estrés hídrico. Cuad. Soc. Esp. Cie. For., 17: 69-74.

Hyndman, S., P. Hasegawa y R. Bressan. 1982. The role of sucrose and nitrogen in adventitious root formation on culture rose shoots. Plant Cell Tissue Organ Cult, 1(2): 29-38.

Ledin, B. 1955. Rubus trials in South Florida, págs. 272-274. Florida StateHorticultural Society. SubTropical experiment Station.

Luna, C., J. Tarragó, P. Sansberro y L. Mroginski. 2004. Enraizamiento in vitro de Ilex dumosa. Universidad Nacional del Nordeste, Facultad de Ciencias Agrarías, Instituto de Botánica del Nordeste. Comunicaciones y Científicas, resumen: A015 .

Ma, Y., D. Byrne y J. Chen. 1996. Propagation of rose species in vitro. In vitro cell. Dev. Biol-Plant, 32: 103-108.

Marulanda, M., M. Carvajalino y H. Vento. 2000. Establecimiento y multiplicación in vitro de plantas seleccionadas de rubus glaucus benth para el departamento de risaralda. Actual Biol, 22(73): 121-129.

Pati, P., S. Prasad, M. Sharma, A. Sood y P. Ahuja. 2005. In vitro propagation of rose - a review. Biotechnology advances. Science Direct, págs. 95-111.
Programa fitosanitario para el agro para la mitigación de barreras técnicas del acceso al mercado de EEUU (PROFIAGRO). 2007. Estudio de factibilidad de mora. Quito-Ecuador, págs. 5-22.

Raisman, J. y A. González. 2008. Reproducción asexual (en línea). República de Argentina, Universidad Nacional del Noroeste. Facultad de Agroindustrias. Hipertextos del área de biología, URL /http://www.biologia.edu.ar/ reproduccion/asexual.htm $\rangle$.

Ramírez, A. y A. Angarita. 1990. Estudios preliminares para la propagación clonal in vitro de mora (rubus glaucus 1.). Agron. Colomb, 7(1-2): 17-25.

Salek, M. y A. Tarinejad. 2011. In vitro multiplication of rose (rose hybrida cv. baccara). AmericanEurasian J. Agric. \& Environ. Sci., 11(1): 111-116.

Wu, J., S. Miller, H. Hall y P. Mooney. 2009. Factors affecting the efficiency of micropropagation from lateral buds and shoot tips of rubus. Plant Cell Tiss Organ Cult, 99: 17-25.

Zanandrea, I., M. Bacarin, D. Schmitz, E. Bolacel y J. Peters. 2006. Chorophyll fluorescence in vitro cultivated apple. Bras. Agrociencia, Pelotas, 12(3): 305-308.

Zarco, P., J. Miller, G. Mohammed, T. Noland y P. Sampson. 2000. Utilización de moelos de reflectancia como nexo entre muestras foliares y la cobertura forestal: aplicación a datos espectrales. Center for research in Earth and Space Science (CRESS). York University, Toronto, Ontario, Canadá.

Zarco, P., J. Miller, G. Mohammed, T. Noland y P. Sampson. 2001. Estimación del contenido clorofílico en coberturas con estructura caducifolia y conífera mediante inversión de modelos de transferencia radiativa y datos hiperespectrales. Teledetección, Medio ambiente y Cambio Global (2001), págs. 160-164. 